\title{
Participación política de pecheros en Castilla tardomedieval: los posibles márgenes de acción entre la diferenciación socioeconómica del sector y la imposición del concejo cerrado*
}

\author{
Political participation of Commoners in Late Medieval Castile: \\ the scope of action between socio-economic differentiation \\ and the imposition of the closed council system
}

\author{
Silvina ANDREA MondRagóN**
}

\begin{abstract}
RESUMEN
A partir de documentación municipal abulense tardomedieval, se rastrean mecanismos políticos de pecheros, tanto de resistencia como de acción concreta, articulados y posibilitados en un marco de centralización de los poderes regios y de intentos señoriales por avanzar sobre la autonomía de las comunidades campesinas. Es en este contexto histórico

particular que se vertebra una «cultura política» propia, pasible de ser rastreada en la documentación a partir de determinadas estrategias, como la demanda de reconocimiento institucional del estamento o las resistencias a la

usurpación de comunales llevadas a cabo por los caballeros de algunos concejos.
\end{abstract}

ABSTRACT This study examines different modes of political participation and representation of Castilian tax-paying commoners in local government, focussing on two conditioning factors: the socio-economic differentiation of their sector and the influence their place of residence, town or country, had on the development of political participation on the part of the peasantry at the turn of the Modern Age. Council sources, both urban and rural, are utilized and contrasted to advance certain explanatory factors for the creation of an autonomous political logic in this sector.

* Fecha de recepción del artículo: 2011-6-23. Fecha de aceptación del artículo: 2012-3-2.

** Docente de la Universidad Nacional del Centro de la Provincia de Buenos Aires (UNCPBA) e investigadora en formación del Instituto de Estudios Histórico-Sociales (IEHS) y del Centro de Historia Social Europea de la Universidad Nacional de La Plata. Ce: silvinamondragon@yahoo.com.ar 
PALABRAS CLAVE

Gobierno local, pecheros, Castilla, "concejo cerrado».
KEY WORDS

Local government, Commoners, Castile, Closed council system

\section{INTRODUCCIÓN}

La realidad castellana de la segunda mitad del siglo XIV ha sido interpretada desde la dimensión política a partir del repliegue y concentración de las estructuras de poder sobre los grupos oligárquicos. En este sentido una amplia historiografía ha considerado que los concejos se habían cerrado a la participación del «Común»1.

Sin embargo, esta tendencia no puede ser presentada como universal en todos los municipios ya que cada concejo de realengo atravesó su propio recorrido con lo que los resultados a nivel de la lógica de representación y de participación política de cada uno de los grupos sociales difirieron de uno a otro, acorde su diferente composición y evolución desde sus orígenes. El equilibrio de fuerzas, locales y monárquicas, a partir del que se había organizado la gestión de los realengos explica en buena medida que el monarca no haya podido implantar ni vertical ni homogéneamente su voluntad centralizadora, por lo que los resultados en cada uno de ellos tampoco fueron uniformes.

Quienes participaban en las instancias disponibles de representación política, y la forma en que lo hacían, eran también el resultado de un largo proceso de construcción de una dinámica de participación. De forma conexa, tampoco puede considerarse al órgano de gobierno a partir de la instauración del regimiento, como el único espacio en el que se ejercía el poder político en el medio castellano del feudalismo tardío.

No obstante, frente a este espacio político complejo y señorializado², se reconoce en los pecheros una más activa y protagónica participación en la gestión del

\footnotetext{
1 Por citar algunos ejemplos: SÁNCHEZ BENITO, J. «El poder en una pequeña ciudad castellana: el ejemplo de Huete en el siglo XV», En la España Medieval, no 25, 2002; MARTínEZ MORO: J. La tierra en la comunidad de Segovia, Valladolid, 1985; COLLANTES DE TERÁN, A.: «Un informe sobre la confección de los padrones de cuantías de Sevilla y su tierra de 1438», Historia, Instituciones, Documentos, no 19, 1992; RUIZ POVEDANO, J.: «Poder, Oligarquía y parcialidades en Alcalá la Real: el asesinato del corregidor Bartolomé de Santa Cruz», HID no 29, 2002; JARA FUENTE, J. A.: «Que memoria de onbre non es en contrario. Usurpación de tierras y manipulación del pasado en la Castilla urbana del Siglo XV», Studia Historica Medieval, no 20-21, 2002-2003.

2 Espacio político señorializado en tanto desde mediados del siglo XIII se abrió en el medio urbano un campo de competencias al interior de los sectores hegemónicos, que se redobló en la forma en que se adecuaban al pasaje de la pertenencia al realengo hacia las formas de dependencia privada señorial, generalmente nobiliarias; en MONSALVO ANTON, J. M: «La participación política de los pecheros en los municipios castellanos de la baja Edad Media. Aspectos organizativos", Studia Historica. Historia Medieval, Vol. VII, 1989, p. 41.
} 
gobierno urbano durante el transcurso del siglo XV. De esta cuestión se derivan una serie de interrogantes iniciales acerca del papel histórico concreto por ellos desempeñado: ¿fueron capaces de articular una lógica política propia?, ¿su actuación política debe ser tenida en cuenta como el resultado de la acción de un grupo socioeconómico coherente o más bien se trataba de un conjunto polimorfo sólo unificado a partir de la obligación del pago de la cáñama ${ }^{3}$ ? En este sentido, la cuestión de fondo gira en torno de responder si los cambios en las formas de control de los concejos de realengo, que a mediados del siglo XIV puso en marcha la monarquía castellana, en lugar de potenciar estrategias en conjunto, tuvieron efectos diferenciados y por ende diversificadores en el seno del «Común».

El escenario en el que se puede rastrear la participación política de pecheros es bifronte: por un lado los concejos de villa en cuyo estudio pueden apreciarse las tensiones políticas y los conflictos económicos y sociales de base entre el sector de los caballeros villanos, que formalmente los monopoliza, y el de los pecheros ${ }^{4}$. Por otra parte, los concejos de aldea fueron el espacio en el que se plasmaba la diferenciación de intereses entre el mundo urbano y el rural ${ }^{5}$ en tanto que centros de gestión alejados del concejo cabecera, lograban escapar con frecuencia a la esfera de dominación directa sobre la que éste podía ejercer un estricto control ${ }^{6}$, permitiendo el desarrollo de instituciones propiamente campesinas como las Universidades de Tierra ${ }^{7}$.

Este trabajo busca reconocer la funcionalidad política del sector pechero ${ }^{8}$ a partir del análisis del medio concejil abulense, y la incidencia que sus mecanismos de reproducción sociopolítica tuvieron en esta área de realengo, a partir de ponderar el análisis de la relación entre la dinámica de participación política y los procesos

\footnotetext{
3 Pueden estar diferenciados por una multiplicidad de variables: por ejemplo por cuestiones económicas como la participación de algunos campesinos enriquecidos en la gestión de la renta o por cuestiones político-culturales perfiladas a partir del lugar de residencia: la vida en el concejo cabecera o en la Tierra de éste daba lógicamente resultados diferentes en cuanto al grado de participación o incidencia política del sector en sus respectivos concejos.

${ }_{4}$ Aunque no sea reconocida en instancias formales de participación, no se puede soslayar que la representación política de pecheros logra concretarse con lo que pueden expresar sus intereses; la idea está contenida en MONSALVO ANTON, J. M. «La participación política de los pecheros en los municipios castellanos de la baja Edad Media. Aspectos organizativos», op. cit.

5 MARTINEZ MORO, J: La tierra en la comunidad de Segovia, Universidad de Valladolid, Valladolid, 1985, p. 151.

6 La hipótesis está contenida en MONSALVO ANTON, J. M: «Las dos escalas de la señorialización nobiliaria del sur del Duero: concejos de villa y tierra frente a señorialización «menor», en Revista d historia medieval, $\mathrm{N}^{\circ}$ 8, 1997.

7 Como muestra Diago Hernando, el hecho de que fuera el concejo de cabecera, reconvertido en regimiento, el que se reservara la capacidad de decisión en los asuntos más importantes, hizo que «la población campesina avecindada en las aldeas dependientes sintiera la necesidad de desarrollar un aparato instituciónal que garantizase la defensa de sus intereses frente a las decisiones tomadas en el concejo cabecera.... en DIAGO HERNANDO, M: «Una institución de representación política del campesinado en la Castilla bajomedieval: las Universidades de Tierra», Historia, Instituciones, Documentos № 23, 1996, p. 286.

${ }^{8}$ Al respecto ASTARITA, C: «Representación política de los tributarios y lucha de clases en los concejos medievales de Castilla», Studia Histórica, Historia Medieval, № 15, 1997.
} 
de diferenciación social entre los pecheros. Se intenta a partir del análisis concreto de Ávila promover una visión general y de conjunto de la dinámica de la cultura política de pecheros en el área castellana de concejos, sin desconocer que la evolución institucional particular de cada uno de ellos dio por resultado equilibrios diferenciados de fuerzas sociopolíticas.

\section{DIFERENCIACIÓN SOCIAL Y PARTICIPACIÓN POLÍTICA DE PECHEROS}

Los procesos de diferenciación social que experimentaron las comunidades campesinas tuvieron clara incidencia en la dinámica política local, a punto tal que llegaron a gravitar en las instancias superiores del reino. Veamos a partir de un ejemplo concreto la intervención de los Reyes Católicos a propósito de un conflicto suscitado entre los vecinos de Bóveda con un vecino del concejo cabecera de Ávila.

El 22 de febrero del año 1500, los reyes Fernando e Isabel decidieron responder a los vecinos de Bóveda tomando cartas en un asunto que revela la incapacidad tanto del concejo rural como del concejo urbano para dirimir un enfrentamiento que desbordaba los dispositivos institucionales municipales.

Hacía ya tres años que el hijo de un tal Gil González, vecino de Ávila, había acuchillado a Alonso del Río y a la mujer de Juan Jiménez, vecinos del lugar de Bóveda, en respuesta a la proclama emanada del concejo aldeano que ordenaba prohibir la entrada al mismo de su padre por interferir en sus asuntos, bajo pena de destierro y expropiación de sus bienes en caso de incumplimiento de la sentencia. Los vecinos lo habían denunciado al concejo de Ávila argumentando que «ha fecho e faze, él e sus fijos e criados por su mandado aviéndolo él por firme e gratto, muchas ynjustiçias e fuerzas e males al dicho conçejo y personas particulares dél»9.

En consecuencia, los Reyes Católicos habían mandado otorgar una carta de seguro al concejo de Bóveda para sellar el compromiso que tenían con los pecheros del concejo rural:

«Por que vos mandamos que dédes e entregédes el dicho concejo e onbres buenos la dicha sentencia que ansy en su fabor fue dada contra el dicho Gil González, e asymysmo la dicha nuestra carta de seguro para que ellos la trayan para guarda de su derecho, mandamos al nuestro corregidor de la cibdad de Avila aque vos constriga e apremye a ello ${ }^{10}$.

No obstante, en enero de aquel año Gil González se apersonó en medio de una reunión del concejo rural y tomando un palo comenzó a atacar a golpes a los

9 GARCIA PEREZ, J: Documentación Medieval Abulense en el Registro General del Sello Vol. 38, Ed. de la Institución «Gran Duque de Alba», Ávila, 1998, doc. 8.

10 GARCIA PEREZ, J: Documentación Medieval Abulense en el Registro General del Sello Vol. 38, op. cit, doc. 9. 
allí presentes hasta que llegó el alcalde Juan del Río ${ }^{11}$, vara en mano, para amedrentarlo y convertirse finalmente en el objeto sobre el que ahora Gil González descargaba toda su furia ${ }^{12}$.

En este clima de violencia que crecía a medida que los distintos actores encontraban en los rasgos personales del otro argumentos para sostener su malestar, se desdibujaba cada vez más la autoridad política pero también la preeminencia social del concejo, como institución con capacidad de someter a coacción a la población asentada sobre los límites de su jurisdicción y sobre la que irradiaba sus prerrogativas jurídicas.

El relato de lo acontecido trasunta un clima de hostilidad al que, evidentemente, no podían oponerse los vecinos con las herramientas de disciplinamiento social que proveía el sistema político local.

Podríamos preguntarnos por qué a comienzos del siglo XVI, vecinos de la Tierra recurrían directamente a los reyes para pedirles su arbitraje, con el claro convencimiento de que no sólo serían escuchados sino que se atenderían sus reclamos; ¿por qué se había convertido en una posibilidad para los pecheros trasvasar los círculos de poder político local y acceder a los dispositivos provistos por la propia monarquía? y sobre todo, ¿sobre qué bagaje de usos o atributos políticos concretos se había naturalizado esta práctica entre ellos?

Estas preguntas cobran mayor sentido cuando advertimos que un mes después, el 23 de marzo de 1500, los reyes mandaron al corregidor de Ávila a remover a uno de los escribanos que atendía en el proceso de los vecinos contra Gil González, a consecuencia de la denuncia de Isabel de Carvajal que acusaba a éste de ser un amigo cercano del denunciado ${ }^{13}$. El relato es importante ya que nos permite resaltar que quienes instigaban a los concejos tanto de Ávila como de Bóveda a enviar sendas cartas a los reyes, eran los vecinos de la Tierra. No sólo dirigían sus peticiones ante la autoridad monárquica, sino que recibían en contrapartida respuestas satisfactorias como el desplazamiento del escribano. Es

11 Resultaría pertinente saber si el apellido Del Río que comparten el vecino acuchillado y el alcalde indica parentesco entre ambos.

12 «e a quererle prender, que el dicho Gil González, con poco temor de Dios y en menosprecio de nuestra justicia e de la bara del dicho alcalde que traya, con el palo que tenía en las manos del dicho Gil González dio de palos que asy le dava le ponía la bara delante por que él tomase asentamiento y en cuidado de la dicha vara de más de los palos que le dio a él le dio muchos palos en la dicha vara», GARCIA PEREZ, J: Documentación Medieval Abulense en el Registro General del Sello Vol. 38, op. cit, doc. 8.

${ }_{13}$ El relato que llega por medio de carta del concejo rural a los reyes cuenta que «... Juan Vázquez, escrivano público desa dicha cibdad, e que es mucho amygo del dicho Gil González e que a esta cabsa e por non querer fazer el dicho Juan Vázquez lo que es obligado en su oficio diz que se han seguido e syguen muchos enojos e ynconvenientes e que non avía podido fazer su provanca la dicha Doña Ysabel e podría perescer su justicia e que sy asy pasase que ella rescibiría mucho agravio e daño", GARCIA PEREZ, J: Documentación Medieval Abulense en el Registro General del Sello Vol. 38, op. cit, doc. 21.

14 Así ha sido argumentado por LUCHIA, C. en «Tierra, poder y violencia en torno a la consolidación de las oligarquías concejiles en el siglo XV: el caso de los caballeros abulenses», Espacio, tiempo y forma, Serie III, N²2, 2009. 
probable que esta práctica tuviera por base la connivencia de los funcionarios regios con los poderes locales ${ }^{14}$.

Aunque ha sido analizado como caballero villano en otros trabajos ${ }^{15}$, la documentación nos permite proponer el siguiente perfil sociológico de Gil González: tenía criados y paniagudos, era amigo personal del escribano y además gozaba de la impunidad necesaria para hostigar al concejo rural de Bóveda durante algo más de tres años, de lo que inferimos el cuadro de un pechero enriquecido de la ciudad de Ávila en franco enfrentamiento con los que seguramente eran otros pecheros enriquecidos: los del concejo rural. Así, es probable que la escena no se corresponda con la clásica oposición de base entre pecheros y caballerías villanas, sino con las disputas entre fracciones de clase tributaria, enfrentadas por el control político del aparato concejil.

En este sentido, además de no ser nombrado como «caballero» en el documento, el peso con que la justicia concejil cae sobre el sujeto parece adecuarse más al perfil de un tributario enriquecido que al de un miembro de la oligarquía:

"sobre lo qual los dichos sus partes traxieron pleito con el dicho Gil González en el nuestro consejo, en el qual fue dada sentencia en que le mandaron que non entrase en el dicho concejo nin entendiese en las cosas dél, so grandes penas e de perdimiento de bienes e destierro, segund que más largo en la dicha sentencia se contiene (...) e la pesquisa fecha e la verdad sabida prendades los cuerpos a los culpantes e presos a su costa con la pesquisa, los enviad al nuestro consejo que en la villa de Valladolid reside, por que ellos lo vean e fagan sobre ello lo que sea justcia. E a los que non pudiérdes aver para los prender los cuerpos les secrestedes sus bienes e les pongades en secrestación e de manifiesto en poder de buenas personas... „16.

La crónica de la participación política de pecheros en instancias reconocidas desde lo formal y jurídico excede cronológicamente los límites de este trabajo ${ }^{17}$ aunque se debe señalar que desde la vertebración del estamento en el siglo XIII se sentaron las bases de su participación, condicionada por el hecho de que al sector de caballeros villanos ${ }^{18}$ se le confió el control militar del territorio con lo que se garantizaba básicamente la extracción del excedente para la instancia de poder superior y la coerción política del señorío colectivo de la villa sobre las aldeas del alfoz. Así, la

15 «Gil González, Gómez Dávila, Esteban Domingo, Pedro de Ávila, Diego de Ávila son caballeros prominentes cuya actuación en la política de la ciudad resulta clave», en LUCHIA, C: «Tierra, poder y violencia en torno a la consolidación de las oligarquías concejiles en el siglo XV: el caso de los caballeros abulenses», op. cit. p. 197.

16 GARCIA PEREZ, J: Documentación Medieval Abulense en el Registro General del Sello Vol. 38, op. cit, doc. 8.

17 En 1115, la reina Urraca convocó a nobles y pueblo al Concilio de Oviedo, en el que determinó que ambos estamentos suscribieran las actas. La nota aparece en COLMEIRO, M: Cortes de los antiguos reinos de León y Castilla. Primera parte, Madrid, 1893 y es reproducido por J. C RUBINSTEIN: ¡Viva el Común! La construcción de la protosociedad civil y la estructura política castellana en el bajo medioevo, Prometeo,Buenos Aires, 2005.

18 Si bien eran de origen campesino, se diferenciaron tempranamente debido a la función militar que cumplieron en pos de la repoblación de la meseta castellana con lo que resultaron la base constitutiva de las oligarquías locales. 
conversión de los grandes concejos en señoríos colectivos supuso la conversión de los antiguos propietarios libres en tributarios, con lo que se reconocía formalmente su condición estamental al amparo de la conformación de un sistema político que facilitaba y procuraba la participación política no sólo de los caballeros sino también de los pecheros ${ }^{19}$.

El ámbito del realengo se estructuró bajo estas condiciones, siendo fundamental la propiedad eminente del monarca, lo que significaba en la práctica que la gestión de estas porciones de patrimonio real no estuviera organizada y controlada directamente por la monarquía ${ }^{20}$. Monsalvo Antón ha referido la noción de realengo transferido ${ }^{21}$, que significaba en la práctica la cesión de una parte importante de la fiscalidad regia al poder local lo que daba la nota distintiva a estos concejos: la gestión de la renta en manos de los tributarios enriquecidos, garantes así de la extracción de excedente para la instancia superior ${ }^{22}$.

Es por este carácter patrimonial que el realengo se perfiló como escenario en el cual se exhibía el juego de alianzas complejas y ambiguas que la monarquía fue tejiendo a lo largo de los siglos bajomedievales en los que los espacios de realengo se convirtieron en bienes de cambio en los pactos políticos que sellaba el rey con las diferentes fuerzas del reino ${ }^{23}$. Este fenómeno que tenía profundas raíces en formas monárquicas patrimoniales se conservaba en apariencia, aunque era la esencia de la intención y contenido de la práctica lo que se había modificado especialmente a partir de los primeros Trastámaras ${ }^{24}$, cuando se convirtió con claridad en una estrategia conciente de la monarquía para articular redes de poder y alianzas convenientes con determinados sectores de la nobleza en detrimento de otros.

${ }^{19}$ Una cronología de la institucionalización política de los pecheros en el trabajo de RUBINSTEIN, J. C: ¡Viva el Común! La construcción de la protosociedad civil y la estructura política castellana en el bajo medioevo, op. cit.

20 Sobre la cesión de tierra realenga a particulares y sus formas de gestión, se puede consultar MONSALVO ANTON, J. M: «Las dos escalas de la señorialización nobiliaria del sur del Duero: concejos de villa y tierra frente a señorialización «menor», op. cit.; sobre condiciones y condicionantes de reclutación de personal judicial no señorial, se puede consultar del mismo autor «El reclutamiento del personal político concejil. La designación de corregidores, alcaldes y alguaciles en un concejo del siglo XV», Studia Historica. Historia medieval, № 5, 1987.

21 Sobre la noción de realengo transferido ver MONSALVO ANTON, J. M: «Centralización monárquica castellana y territorios concejiles (algunas hipótesis a partir de las ciudades medievales de la región castellana leonesa», en Anales de la Universidad de Alicante N 13, 2000/2002.

22 Una originalidad del área de concejos es que el poder señorial no interviene en el arrendamiento de rentas: «Las disposiciones relativas a quiénes están facultados para la tarea aluden al campesino rico y prohíben que participen de ella la justicia y regidores de la villa (...) de todos modos la documentación sugiere que es el sector de pecheros el que predomina, al amparo de relaciones de tipo clientelar con los regidores», en DA GRACA, L: Poder político y dinámica feudal. Procesos de diferenciación social en diferentes formas señoriales, siglos XIV-XVI,Valladolid, 2009, p. 154.

${ }^{23} \mathrm{Al}$ respecto ver SANCHEZ, B: «El poder en una pequeña ciudad castellana: el ejemplo de Huete en el siglo XV», En la España Medieval, № 25, 2002 y DIAGO HERNANDO, M: «El común de los pecheros de Soria en el siglo XV y primera mitad del XVI», Hispania, L/1, № 174, 1990.

${ }_{24}$ MONSALVO ANTON, J. M: La Baja Edad Media en los siglos XIV - XV, Madrid, 2000, p. 128. 
En 1345, cuando Alfonso XI instauró el Regimiento en Ávila ${ }^{25}$, se había previsto que un tercio de las regidurías cayeran en manos pecheras aunque en la práctica se hizo imposible sostener la proporción ya que se plasmaban en esta institución las luchas intra señoriales ${ }^{26}$ y los resultados del proceso de diferenciación social que había atravesado al estamento pechero, agudizado desde mediados del siglo $\mathrm{XIV}^{27}$.

El realengo había permitido la incorporación de los pecheros al gobierno concejil como procuradores pecheros sexmeros o de la Tierra y/o regidores, al tiempo que se dejaba en manos de la caballería villana el control de los medios de coerción, necesarios para garantizar el cobro de la renta que estaba destinada al poder central.

En un trabajo ya clásico ${ }^{28}$, María Asenjo González sostuvo que la aparición de un sector de labradores ricos en la Tierra de Segovia a fines del siglo XV modificó el equilibrio de fuerzas del área en tanto se perfilaron como grupo de poder económico, político y social mejor posicionado que sus pares de la ciudad (pequeños mercaderes y artesanos) para lograr la consecución de sus intereses en tanto ésta solo dependía de una transferencia menor de competencias del concejo cabecera hacia los concejos rurales. La autora sostiene que se habían constituido en una oligarquía rural, con capacidad de accionar políticamente la defensa de sus intereses y de consolidarse como sector coherente y definido, en tanto no trataban de emular las formas de vida de la caballería, por lo menos en sus mecanismos de reproducción simbólica, aunque su solvencia económica proviniera de su condición de grandes propietarios de tierras y ganado.

Como es de suponer, este trabajo pionero abrió el juego a la evaluación de la actividad política de los pecheros castellanos medida básicamente por el acceso que tuvieron, o lograron, a los cargos y oficios que la imposición del regimiento había limitado. Jara Fuente ha interpretado que esta incorporación de los no privilegiados al gobierno constituiría una forma de atenuar la conflictividad que el sector mantenía con las oligarquías, pero también una estrategia del rey para delimitar el control del

25 El Regimiento implicaba un sistema político cerrado y controlado por la monarquía, que legaba el peso de la toma de decisiones municipales en los cargos de regidor y alcalde.

${ }^{26}$ En el caso de Segovia, por ejemplo, el Regimiento se situó al margen del control comunal debido a que los regidores eran nombrados por el monarca y sólo de su voluntad dependía el mantenimiento del cargo, lo que explica en buena medida el sentido de prebenda con que fue utilizada esta institución por parte de la monarquía. Ver MARTINEZ MORO, J: La Tierra en la comunidad de Segovia. Un proyecto señorial urbano, 1088-1500, Valladolid, 1985.

27 Obviamente, la polarización del campesinado no impide su consideración como clase, determinada por la obligación de tributar y por la exclusión del privilegio. En este sentido, Monsalvo Antón ha sostenido que «hay una identidad mínima: su condición de no privilegiados, de contribuyentes. En ella se sustentaba una toma de conciencia elemental — sin ella no hay acción política - sobre su situación, percibida explícitamente de manera inmediata y seguramente concebida bajo esquemas de estratificación social. Era además una toma de conciencia que había surgido pronto, mucho antes de la implantación del Regimiento», en MONSALVO ANTON, J. M.: «La participación política de los pecheros en los municipios castellanos de la baja Edad Media. Aspectos organizativos», op. cit., p. 40.

${ }_{28}$ ASENJO GONZALEZ, M: «Labradores ricos: nacimiento de una oligarquía rural en la Segovia del siglo XV», En la España Medieval, N 4, 1984. 
gobierno concejil que éstas detentaban ${ }^{29}$. Por su parte, Monsalvo Antón ha demostrado que precisamente a mediados del siglo XIV se desarrollaron todas las potencialidades políticas del sector pechero ${ }^{30}$ lo que se evidenciaba, por ejemplo, cada vez que hacían sentir su voz en defensa del aprovechamiento de los terrenos comunes y en contra de las usurpaciones fraudulentas de éstos por parte de caballeros y señores, lo que derivaba en su enfrentamiento con las oligarquías urbanas ${ }^{31}$.

Sin embargo, debemos preguntarnos si los pecheros en conjunto usufructuaban instancias de representación política de forma indiferenciada, ya que no podemos soslayar los efectos del proceso de diferenciación social del sector que se manifestaba con claridad en el hecho de que los labradores más enriquecidos se habían convertido en empleadores de trabajo asalariado y por tanto extractores de plustrabajo de su propia comunidad; no obstante se debe resaltar la diferenciación sustantiva entre labriegos enriquecidos y otros devenidos miembros de las oligarquías que, habiendo logrado ser exentos de pechos, articulaban la dominación del poder central sobre el campesinado en el nivel local ${ }^{32}$.

La incidencia de las políticas del poder central sobre el desarrollo de la polarización social de los no privilegiados se entiende cuando se revisa la forma en que se organizaba el cobro de la renta y, sobre todo, cómo se estipulaba lo que cada uno debía tributar. En el medio fiscal castellano, el sistema de cáñamas implicaba formalizar y profundizar la desigualdad, ya que existían diferentes tasas de renta de acuerdo al resultado de la tasación personal de bienes; de lo cual se derivaban diferencias sustantivas en las cantidades a pagar. Se formalizaba así la desigualdad

${ }^{29}$ Hipótesis contenida en JARA FUENTE, J. A: «Estructuras formales de poder y de organización de las clases dominantes urbanas en castilla. El regimiento: una crisis del siglo XIV en el siglo XV», Edad Media. Revista española de Historia N 8, 2007.

30 MONSALVO ANTON, J. M: «Percepciones de los pecheros medievales sobre usurpación de términos rurales y aprovechamiento comunitarios en los concejos salmantinos y abulenses», en Edad media, Revista de Historia, 7, 2005-2006. Una de las hipótesis que sostiene el autor, propone que la anulación política que representó el regimiento, estimuló en los pecheros las ganas de organizarse políticamente como mecanismo de resistencia; lo que mostraría la evidencia concreta de la existencia de conciencia de clase estamental.

31 En la documentación concejil del período tardomedieval es abundante la evidencia de lo señalado. Suele aparecer bajo formulaciones como la que sigue: «...teniendo el dicho concejo de tienpo ynmemorial acá sus términos e mojones que le fueron dados para los vezinos e pecheros e moradores en el dicho lugar por los reyes antepasados de gloriosa memoria, dado por privilegio dello, diz que algunos ciertos vezinos de la dicha cibdad especialmente García Serrano e Alonso del Sello e la muger e fijos de Pedro Sánchez Bermejo e Suser de Miruela, capellán desa dicha cibdad, con favores e parentela que tienen e con los muchos ganados e yeguas e bueyes e vacas e otros, a cabsa de alguna heredad que ally tienen diz que se an tanto señoreado en el dicho lugar que ellos por sy con sus ganados an cortado los montes e pacido e pacen las yervas e tierra... "CANALES SANCHEZ, J: Documentación medieval abulense en el Registro General del Sello, vol. VI, Ávila, 1996, doc. 29.

${ }^{32}$ Un análisis de la funcionalidad de la élite de pecheros en ASTARITA, C: Del feudalismo al capitalismo. Cambio social y político en castilla y Europa Occidental, 1250-1520, Universidad de Valencia y de Granada, 2005, «Procuradores pecheros», pp. 113-144. Astarita sostiene que la complejidad tipológica de los procuradores deviene de su condición dual: el empresario calculador y el campesino tradicional en una misma persona que aspira al estatuto de privilegiado; lo que suponemos, puede generalizarse para el total del estrato enriquecido. 
social del estamento pero también se exacerbaban los antagonismos y conflictos del sector. Hay que sumar a esto el hecho de que eran los pecheros mayores los que se ocupaban del cobro de los tributos y de la tasación de bienes, con lo que se manifiesta la preeminencia que tenían en los espacios locales y sobre todo en el ámbito de las aldeas donde no tenían que competir con el poder y los privilegios de las oligarquías ${ }^{33}$.

Así, se vuelve paradójica la lógica de la extracción del excedente campesino en Castilla tardomedieval ya que el sistema permitía que la fracción enriquecida del sector pechero cobrara la renta en los alfoces. En suma: un vecino por todos conocido tenía mejores perspectivas de materializar el cobro de la renta y al mismo tiempo presentarse como un defensor de los intereses políticos del estamento. En este sentido, podemos sostener que estos pecheros enriquecidos ejercían una dominación política de hecho en los concejos rurales ${ }^{34}$.

A nivel del disciplinamiento social, el estrato enriquecido del sector pechero era funcional a la reproducción de la lógica de control social imperante, con lo que la exención tributaria, que algunos de sus miembros conseguían, constituía una prebenda económica indiscutible. Sin embargo, es probable que se tratara de un mecanismo eficaz de domesticación política de estos pecheros enriquecidos, instrumentado por el poder central ya que aseguraba el favor constante de la persona sobre la que había recaído el beneficio. En este sentido, en un documento de la colección diplomática de Cuenca se observa que en un pleito de hidalguía se arguyen las diferentes formas de exención tributaria, entre las que se cuentan: los «arreglos» con los oficiales del concejo aldeano, en primer lugar y en segundo, distintas estrategias como el acceso al cargo de oficial del concejo o bien situaciones más informales como aquéllas en que se menciona el hecho de complacer a los recaudadores pecheros, con el fin que estos puedan ostentar su capacidad de excu-

33 DA GRACA, L: Poder político y dinámica feudal. Procesos de diferenciación social en diferentes formas señoriales, siglos XIV-XVI, op. cit, Segunda Parte, cap. 1.

${ }^{34}$ En enero de 1414 se suceden dos importantes procesos judiciales por usurpación de términos, en la que un tal Alfonso Sánchez, vecino de El Tiemblo actúa en representación de la Tierra de Ávila y lidera claramente los términos del proceso judicial; sendos documentos en LUIS LOPEZ, C. y DEL SER QUIJANO, G: Documentación medieval del Asocio de la Extinguida Universidad y Tierra de Ávila, Ávila, 1990, doc. 74 y 75; otro ejemplo que podemos citar de intervención de campesinos enriquecidos de la Tierra, a través de instituciones típicamente pecheras, es el mandamiento del alcalde de Ávila que en abril de 1498 ordena que no se pague a los arrendadores de pan un precio más alto del que se había estipulado en tiempos de la toma del arrendamiento por pedido expreso de Francisco de Pajares, procurador general de la Tierra y pueblos de Ávila, quien tenía en su poder una carta emitida por los Reyes que respaldaba su petición: «Yo, el bachiller Pedro de Ayllón, alcalde en la noble cibdab de Ávila, hago saber a vos, los concejos, alcaldes e omnes buenos del lugar de Riofrío e a cada uno e cualquier de vos, que ante mí pareció Francisco de Pajares, procurador general de la tierra e pueblos de la dicha cibdad, e presentó ante mí una carta del rrey e rreyna nuestros señores, escripta en papel e fyrmada de sus rreales nombres de los del su muy alto consejo, segund que por ella parecía, en que en la dicha carta mandan sus altezas que agora e de aquí adelante non se pyda nin demande a los concejos e vezinos de los lugares de la tierra (...) que les aya de dar e pagar de los dichos votos a más precio de conmo valía en los años pasados», en DEL SER QUIJANO, G: Aportación al estudio de Riofrío en la Edad Media, Ávila, 1998, 15. 
sar a otros ${ }^{35}$. Todo esto claramente muestra la importancia de los beneficios que la exención tributaria significaba para los labradores ricos que podían acceder a ella.

Eran estos personajes los que conformaban las filas de las elites pecheras y los candidatos naturales para materializar la defensa de los intereses pecheros, aunque esa representación se ejercía sobre un sector que no era homogéneo, lo que reforzaba a su vez el margen de maniobra discrecional que estas elites tenían a la hora de expresar los reclamos de los pecheros: no es una novedad que tuvieran intereses encontrados los labradores enriquecidos y aquellos que habían quedado marginados de los beneficios. En este sentido, la contradicción era una columna sustantiva de la conformación de la elite pechera como un segmento de clase con poder político propio.

El sector social de los pecheros aparece claramente diferenciado a los ojos de los historiadores del período no sólo por la polarización del estamento a partir de la posesión o no de riqueza sino porque tampoco se puede soslayar la diferencia de intereses y oportunidades sociopolíticas entre los que habitan la Tierra y los que habitan en la villa: algo básico es subrayar que los primeros estaban atravesados por siglos de tradición comunitaria que se sustentaba en fuertes lazos de solidaridad campesina, lo que a su vez se manifestaba por ejemplo, en que fuera posible la defensa colectiva de los comunales o las resistencias, también comunitarias, a las proclamas injustas de exención de pechos, lo que deja al descubierto las fracturas internas de la comunidad rural ${ }^{36}$.

Los pecheros de la Tierra se diferenciaban a grandes rasgos de los pecheros que habitaban en el concejo cabecera en gran parte porque estos últimos, en contacto directo con las prácticas políticas del concejo de villa, convivían en la dinámica de lo cotidiano con los caballeros villanos; en un marco que propiciaba la interacción con otros poderes políticos, sobre todo los de incidencia regia. Estas condiciones también propiciaban el intento por parte de los pequeños comerciantes y artesanos de emular el nivel de vida, tanto simbólico como material, de la caballería villana. Esto último es lo que, a nuestro entender, anulaba de base el despliegue de estrategias políticas autónomas y propias de los pecheros enriquecidos de la villa en tanto y en

35 «... en caso que en algund tiempo/usurpando el estado e ábito de fijosdalgo que sería de fecho allegándose a algunos poderosos engannosamente por se escusar e refuyr/ de la sujeción dello, o por ser arrendador de los pechos e derechos reales e concejales de la comarca donde vevía e venía, por se/ escusar asy mismo o por ser ordenado de órdenes de Santa Yglesia, o por caballería de alarde o por privilegios del dicho lugar o por gracia o por ruegos o por non tener de qué pechar o por ser escusado de los que tenía algund privilejo o escusados o por contentar/ascondidamente a los arrendadores o cogedores o recabdadores porque dyxiesen en placa que lo dexavan commo a omne hijodalgo, o por se pasar de un lugar a otro al tiempo de pechar, o por avenencia con los concejos dende veniera o venía..", CHACON GOMEZ MONEDERO, F. A: Colección diplomática del concejo de Cuenca 1190.1417, Cuenca, 1998, doc. 179.

${ }_{36}$ Abundan en la documentación castellana tardomedieval disputas por exenciones de impuestos, entre las cuales los pleitos de hidalguía adquieren un lugar predominante. Sólo citamos algunos ejemplos: LUIS LOPEZ, C: Poder y Privilegio en los Concejos abulenses en el siglo XV: la documentación medieval abulense de la sección mercedes y privilegios del Archivo General de Simancas, Ávila, 2001, doc. 4, 7, 22 y 29; MONSALVO ANTON, J. M: Documentación medieval abulense en el Registro General del SelIo, Vol. XIV, Ávila, 1995, doc. 44. 
cuanto estaban mas ocupados en copiar el modelo de ascenso social de la caballería que en desplegar intereses diferenciados y propios del sector al que pertenecían.

La confrontación fundamental entre señores y campesinos, articulada en torno a la renta feudal, debe ser puesta a jugar en el contexto más general del conocimiento de las diferentes fracciones sociales que estaban en la base de la estructuración y también de la dinámica de los concejos castellanos ${ }^{37}$. De este modo pueden reconocerse otros ejes de disputas que complejizan la dinámica de la conflictividad bajomedieval y temprano moderna.

\section{LUGAR DE RESIDENCIA Y PARTICIPACIÓN POLÍTICA DE PECHEROS: UN PROBLEMA SUBORDINADO}

Una diferenciación básica entre los pecheros de la ciudad y los de la tierra, no obstante su común obligación de tributar, es que entre ellos mediaba una fractura que imposibilitaba la acción política conjunta en pos de idénticos intereses.

Los vecinos de la ciudad se beneficiaban, claro que en escalas muy distintas -ya fueran caballeros o pecheros-, del control sobre la tierra que se concretaba en la centralización del aparato de justicia y también en un férreo control sobre las decisiones locales, la centralización del mercado con la implantación de procesos de producción y distribución que privilegiaban a los vecinos de la ciudad y entre muchos otros, también la fiscalidad que se hacía descansar en gran medida sobre los campesinos que habitaban la Tierra.

Uno de los enfoques más clásicos que ha guiado el análisis de la relación funcional que existía entre las ciudades y su hinterland en el Antiguo Régimen, ha sido entender el espacio rural como un sistema socioproductivo orientado a abastecer a las concentraciones urbanas de alimentos, o materias primas, para que éstas pudieran completar el circuito productivo con la elaboración de manufacturas. Poder determinar cuál era el resultado político, si es que lo había, de esta ecuación a nivel de la capacidad de acción política de los pecheros de la villa o de la Tierra, contribuiría a conocer con mayor precisión estas sociedades. Es por esto que el conflicto entre pecheros de Bóveda y Gil González, un pechero enriquecido de Ávila, nos invita a pensar si es posible abordar al estamento pechero sólo a partir del marco socio económico o resulta necesario, tal como aquí sostenemos, tener en cuenta también la práctica política concreta que se deriva de la vida cotidiana en espacios socioculturales diferenciados.

Monsalvo Antón ha sostenido que una de las variables que permiten analizar las profundas divisiones socioeconómicas que dividían al estamento pechero en el

37 Es una idea fuerza que vertebra la tesis doctoral de MONSALVO ANTON, J. M: El sistema político concejil. El ejemplo del señorío medieval de Alba de Tormes y su concejo de villa y tierra, Universidad de Salamanca, Salamanca, 1988. 
siglo XV, son las posibilidades de acción política concreta que devienen del lugar de residencia: el campo o la ciudad ${ }^{38}$. Así, sostiene que fueron los campesinos que habitaron la Tierra de los grandes concejos de realengo, los que a partir del siglo XV lideraron la defensa de los comunales, se opusieron a los grupos oligárquicos y sostuvieron su autonomía comercial. Por el contrario, Diago Hernando ha planteado que los pecheros de la villa tenían mayor ímpetu político que los de la Tierra $^{39}$, atendiendo a la convivencia en la «ciudad» con burgueses desplazados de la posibilidad de acceder a cargos de importancia municipal, lo que daría al estamento pechero un entrenamiento político bifronte: resistir los embates del concejo cabecera, presentado por el autor como el telón de fondo sobre el que se proyectaba cada vez con mayor nitidez el proceso de señorialización de los linajes y habilitar condiciones de alianza, negociación y confrontación con aquel sector social de tardía aparición ${ }^{40}$.

Acordamos con Monsalvo Antón en que son los pecheros de la Tierra los que lideraron la acción política concreta en la Castilla tardomedieval, dada la contundente evidencia en la documentación concejil de articulación de estrategias políticas originales y propias que les permitieron enfrentar el poder de las oligarquías urbanas y resistir de múltiples formas al proceso de señorialización de las elites urbanas a través del acceso a los mecanismos de negociación directa con la monarquía. Esto implica proponer que tanto la diferenciación social del estamento como el lugar de residencia afectaban la forma en que se articulaban las lógicas políticas en el área concejil de realengo castellana a fines de la Edad Media.

Para demostrar esta hipótesis, nos basaremos en las Ordenanzas medievales de Ávila ${ }^{41}$ a partir de las que es posible ponderar dos variables básicas para reconocer las potencialidades políticas que tuvieron los pecheros en concejos de villa o de tierra, respectivamente: a) las tensiones derivadas de la forma en que se organizaba y controlaba el abastecimiento de cada uno de estos espacios y b) los conflictos en torno del aprovechamiento de comunales. Los ejemplos que citamos a continuación, permiten el análisis del eje de lo político en la dimensión espacial villa-Tierra.

Respecto del primer punto, podemos citar como ejemplo que en 1483 el concejo cabecera mandó a los concejos de Tierra nombrar a un vecino (con probabilidad a un tributario enriquecido) para que se encargara de cobrar el derecho que correspondía pagar a los foráneos que vendían por los campos (sobre todo

38 MONSALVO ANTON, J. M., «La participación política de los pecheros en los municipios castellanos de la baja Edad Media. Aspectos organizativos», Studia Histórica. Historia Medieval, op. cit.

39 DIAGO HERNANDO, M: «Una institución de representación política del campesinado en la CastiIla bajomedieval: las «Universidades de Tierra», Historia, Instituciones, Documentos, № 23, 1996, p. 294.

40 DIAGO HERNANDO ha sostenido que «el común de pecheros de Soria era la institución más proclive a servir de base para aglutinar la oposición política al régimen de gobierno oligárquico encarnado por los regidores y otros altos oficiales elegidos entre los caballeros hijosdalgo», «El común de los pecheros de Soria en el siglo XV y primera mitad del XVI», Hispania, L/1, N 174, 1990, p. 43.

${ }^{41}$ MONSALVO ANTON, J. M: Ordenanzas medievales de Ávila y su Tierra, Vol. V, Ed. de la Institución «Gran Duque de Alba», Ávila, 1990. 
vino), lo que significaba que se otorgaba el beneficio del cobro de un impuesto al medio rural:

«Pero que pueda qualquier fiel de los dichos fieles de los dichos seysmos poner en cada concejo un ome cualquier, para que coja el derecho de los que andan vendiendo vyno de aldea en aldea e de los azeyteros e de todos los otros que con derecho han de pagar e non son naturales del concejo ${ }^{42}$.

La nota que citamos no muestra a simple vista una situación conflictiva entre campo y ciudad ${ }^{43}$, sin embargo es indicativa de los esfuerzos que sostenía la Tierra por conseguir cierta autonomía comercial, como se evidencia, por ejemplo en la resistencia que también esta sostenía frente a los intentos de la ciudad por imponer a sus oficiales en el medio rural. El hecho de poder nombrar a sus propios funcionarios hacía que los pecheros de la Tierra pudieran accionar políticamente para que fueran respetadas sus lógicas productivas y sobre todo, se protegiese el espacio físico en el que éstas se materializaban ${ }^{44}$.

El segundo aspecto al que debemos dedicar atención es al aprovechamiento de los terrenos de uso común ${ }^{45}$. Este eje de análisis se impone dada la contundente evidencia de acción de pecheros, en especial los de la Tierra, en favor de la defensa de los comunales en la documentación concejil del período, por lo que es posible que hayan tenido un mayor peso político con mecanismos participativos diferenciados respecto de los pecheros de la villa como consecuencia, en buena medida, del lugar en el que residían y por ende de las diferentes prácticas y tradiciones socioculturales que el medio les imponía, lo que marcaría en buena medida la

\footnotetext{
${ }^{42}$ MONSALVO ANTON, J. M: Ordenanzas medievales de Ávila y su Tierra Vol. V, op. cit, doc. 7, p. 40.

${ }^{43}$ La imagen que emana de la documentación es la del concejo urbano entronándose como un veedor imparcial con capacidad de acción para garantizar por ejemplo, la transparencia de las transacciones comerciales. Se encuentran fórmulas del tipo: «cualquier carnicero e carniceros que vendieren puerco fresco en Ávila e en sus arravales e en sus términos que lo vendan por peso, asy conmo el concejo e fieles pusieren, salvo lenguas en adobo. E, sy de otra guisa lo vendieren, que por la primera vez pague cada uno dellos diez maravedís e por la segunda vez veynte maravedís e por la tercera vez treynta maravedís; e esta pena que sea para los fieles", en: MONSALVO ANTON, J. M: Ordenanzas medievales de Ávila y su Tierra Vol. V, op. cit., doc. 7.

${ }^{4}$ CANALES SANCHEZ, J. A: Documentación Medieval Abulense en el Registro General del Sello, Vol. VI, Ed. de la Institución "Gran Duque de Alba», Ávila, 1996, docs. 12 y 14; en junio de 1496, los vecinos de la Tierra de Ávila (sexmos y pueblos es como aparecen mencionados los del Común en la documentación) solicitan a los Reyes que ordenen al corregidor de Ávila que restituya las facultades de los escribanos de la tierra que había sido cercenada por los escribanos de la ciudad; en noviembre del mismo año y a petición nuevamente del Común, se ordena restituir penas que antaño cobraban regidores de Madrigal; en: SOBRINO CHOMON, T: Documentación Medieval abulense en el Registro General del SeIlo, Vol, 34, Ed. de la Institución «Gran Duque de Alba», docs. 28, 52 y 53 respectivamente.

45 Sobre el tema los trabajos de LUCHIA, C: «Propiedad comunal y dedicaciones productivas en el área concejil castellana bajomedieval», en Studia Histórica. Historia Medieval, № 23, 2005; «Poderes locales, monarquía y propiedad comunal en los concejos de realengo castellanos bajomedievales» en Anales de la Universidad de Alicante. Historia Medieval, N 15, 2006-2008.
} 
cohesión que el sector ${ }^{46}$ al tiempo que evidencia que planteaban sus reclamos en las máximas instancias de poder del reino ${ }^{47}$.

Como ejemplo de lo anterior, en marzo de 1403 los pecheros del concejo de Serrezuela lograron que el Alcalde de Ávila les devolviese términos del concejo rural que habían sido usurpados por una viuda, Urraca González, luego de lo que parece una jornada de intensa insistencia campesina, que traduce claros intereses económicos y políticos del sector:

Los pecheros «dixieron que le querían luego mostrar, por ende que le requerían e afrontavan de parte del dicho señor rrey, así conmo justicia e juez que era en la dicha cibdad et en su tierra, que fuese luego con ellos al dicho término, et que ellos ge lo querían mostrar el agravio que les era fecho, et lo desfeziese; et sy así lo feziese, que faría bien e derecho, en otra manera dixieron que protestavan de se querellar del al dicho señor rrey o aquien de derecho deviesen (...) et fueron contra la dicha defesa de Avellanosa con el dicho acalde (...) et desto todo cónmo pasó los dichos omes buenos del dicho concejo pedieron a mí el dicho escrivano que ge lo diese así signado»48.

El documento citado nos lleva a un problema analítico vinculado al de la participación política de tributarios en el marco del «concejo cerrado»: el de la dinámica del poder local en relación al regional y sobre todo al central. Sin abocarnos a este tema, sólo haremos dos referencias que a los fines de este trabajo, permiten resaltar que lejos de anular políticamente al campesinado, el cerrojo participativo que el proceso de señorialización intentaba imponer al Común, en realidad propició lo contrario y reforzó especialmente a los de la Tierra.

Así, en 1415 Juan II llegó a exhortar a su corregidor abulense a cumplir su voluntad, ya que los vecinos pecheros informaron al rey de los abusos del funcionario:

«... sabedes en cónmo por otra mi carta vos enbié que, por quanto don Rruy Lópes de Dávalos, mi condestable de Casilla, e Ferrán Gómez, señor de Villatoro, e Diego Goncáles del Aguila e otras personas, vezinos de la dicha cibdat de Avila e de

46 Para el análisis de estrategias defensivas de las comunidades campesinas ver JARA FUENTE, A: «Que memoria de onbre non es en contrario»: usurpación de tierras y manipulación del pasado en la Castilla urbana del siglo XV», Studia historica. Historia medieval, № 20-21, 2002-2003 .

47 Sin embargo, esta afirmación hay que sopesarla desde lo historiográfico ya que varios autores han sostenido que los grandes señores de ganados, de base nobiliar, fueron los que defendieron la preservación de los pastos de acceso libre, ya que su actividad económica se beneficiaba directamente de ello. Se puede oponer a esto que es engañosa la perspectiva puesto que la «preservación» señorial pudo haber escondido en realidad formas indirectas de apropiación que terminaron finalmente por negar el acceso de la comunidad a los pastos. Algunos ejemplos en: RAMOS CLEMENTE, J: «Valdetorres, de dehesa a aldea (1409 - 1510). Doblamiento, conflicto y poder en la Tierra de Medellín», Studia Historica. Historia Medieval, Vol. 20-21, 2002-2003; LOPEZ RODRIGUEZ, C: «La organización del espacio rural en los fueros de la Extremadura castellana», En la España Medieval, Vol. 12, 1989; BERNAL RODRIGUEZ, A: «La tierra comunal en Andalucía durante la Edad Moderna», Studia Historica. Historia Moderna, Vol, 16, 1997.

48 LUIS LOPEZ, C. y DEL SER QUIJANO, G: Documentación medieval del Asocio de la Extinguida Universidad y Tierra de Ávila, op. cit, doc. 55. 
su tierra e en otras partes, avían puesto suspecion en el bachiller Niculás Pérez, que yo avía enbiado por mi inquisidor a la dicha cibdat de Avila e su tierra para fazer pesquisa e inquisycion sobre rrazón de ciertos términos (...) e agora los dichos omes buenos pecheros de la dicha cibdat de Avila e de su tierra enbiáronseme querellar e dizen que, conmoquier que por su parte la dicha mi carta vos fuera mostrada e pedido e rrequerido que la conpliésedes, que lo non avedes querido nin queredes fazer (...) e además sy lo asy fazer e conplir non quesyéredes mando al omne que vos esta mi carta mostrar que vos enplaze que parescades ante mí en la mi corte, dondequiera que yo se ....»9.

El documento citado nos permite inferir que los pecheros de la Tierra lograron enlazar sus intereses a los propios de la Corona, evidenciando con sus denuncias y reclamos los riesgos que le depararía a ésta el crecimiento discrecional de los poderes locales. En este sentido, el juego de alianzas que establecieron los Trastámaras con las oligarquías y con los pecheros en particular, parece ser resultado de los límites impuestos por condiciones materiales que hacían a la reproducción social del campesinado ${ }^{50}$ como base productiva e impositiva.

En este sentido, en 1442 encontramos un pedido expreso de los procuradores sexmeros a Juan II:

«...Muy poderoso señor, vuestra alta señoría vee los trabajos e detrimentos que universal e particularmente están en vuestra corona real (...) por ende muy omillmente suplicamos a vuestra real majestad que por las cabsas susodichas e que se podrían decir, e especialmente porque, segund lo dado, lo que adelante se diere redundaría en diminuyción, e propiamente división e alienación de vuestros regnos e señoríos e de vuestra corona real (...) ordene vuestra señoría que non podades dar de fecho nin de derecho nin por otro algund título enajenar cibdades nin villas nin aldeas nin logares nin términos nin jurediciones nin fortalezas de juro de heredad nin cosa alguna dello... ${ }^{51}$.

La contundencia de la respuesta real refuerza el argumento de la relación funcional de intereses entre la corona y los pecheros:

«...Es mi merced de mandar e ordenar e mando e ordeno por la presente, la qual quiero que aya fuerca e vigor de ley e pacción e contracto firme e estable, fecho e firmado e unido entre partes, que toda las ciudades e villas et logares míos e sus fortalezas e aldeas e términos e jurediciones e fortalezas ayan seydo e sean de

49 LUIS LOPEZ, C. y DEL SER QUIJANO, G: Documentación medieval del Asocio de la Extinguida Universidad y Tierra de Ávila, op. cit, doc. 96.

50 LUCHIA ha resaltado lo que podría ser la esencia del fenómeno al sostener que se trataba del «mecanismo de la corona para consolidar las bases materiales de la masa tributaria, al tiempo que articula un juego subordinante de reciprocidades con los ingentes grupos locales que constituirán las oligarquías concejiles» en: Estrategias de acumulación patrimonial de las elites concejiles en la tierra de Ávila en el siglo XV, Tesis de doctorado de la FF y L de la UBA, defendida en 2009. INEDITA, p. 182.

51 BARRIOS GARCIA, A., MONSALVO ANTON, J. M. y DEL SER QUIJANO, G: Documentación medieval del Archivo Municipal de Ciudad Rodrigo, Salamanca, 1988, doc. 308. 
su natura ynalienábiles e inperescriptíbiles para sienpre jamás e ayan quedado e queden sienpre en la corona real de mis regnos „52.

Como hemos dicho, Monsalvo Antón ha asociado a los labradores enriquecidos de la Tierra con los elementos políticamente más dinámicos ya que se convirtieron en los verdaderos oponentes de los concejos señorializados dado que compartían intereses económicos y políticos definidos como esquema alternativo al de las oligarquías urbanas ${ }^{53}$. Compartimos con Monsalvo Antón este argumento, y agregamos que es probable que estos intereses se enfrentaran también con los de los pequeños comerciantes y artesanos enriquecidos de las villas, desdibujados por sus intentos de identificación con los sectores oligárquicos urbanos y por tanto «desmovilizados» políticamente por estos mismos sectores a los que aspiraban pertenecer ${ }^{54}$, lo que nos permite inferir que los pecheros enriquecidos de las ciudades no lograron articular una lógica política propia, a diferencia de sus pares de las aldeas. Es en este contexto en el que presentamos a Gil González como un pechero enriquecido de Ávila enfrentado con los labradores enriquecidos del concejo rural de Bóveda.

\section{CONCLUSIONES}

Los labradores enriquecidos de la Tierra en Ávila lograron conformar hacia el siglo XV una lógica política propia que les permitió canalizar políticamente sus intereses. Sin embargo, esto no significaba necesariamente su plasmación a nivel de la representación del estamento pechero en las instituciones de poder formal, lo que obliga a un análisis de lo político que exceda lo meramente institucional.

Frente al muro que representaban las oligarquías urbanas en los planos de decisión política local, los pecheros enriquecidos de la Tierra encontraron en la monarquía, y en el espacio concejil rural, un eco que posibilitaba su acción política y con el que era posible reforzar los mecanismos que los defendían de los embates oligárquicos.

El caso de los vecinos de Bóveda contra Gil González, tal vez deba ser analizado a la luz de conflictos intraestamentales que sostenían los pecheros enriquecidos entre sí y que estaban también determinados a partir del lugar de residencia. Campo y ciudad compartían un sector pechero claramente diferenciado a partir de la riqueza pero diferenciado por la experiencia cotidiana del espacio geográfico en

52 BARRIOS GARCIA, A., MONSALVO ANTON, J. M. y DEL SER QUIJANO, G: Documentación medieval del Archivo Municipal de Ciudad Rodrigo, op. cit, doc. 308

53 «Dentro de los pecheros aldeanos parece haberse desarrollado por todas partes durante el período bajomedieval un sector de labradores ricos (...) en ellos posiblemente residía la fuerza de oposición más firme al ejercicio del señorío urbano por los concejos principales y sus tendencias prooligárquicas», MONSALVO ANTON, J. M: «La participación política de los pecheros en los municipios castellanos de la Baja Edad Media. Aspectos organizativos», op. cit, p. 45.

54 Esta hipótesis está contenida en MONSALVO ANTON, J. M: «La participación política de los pecheros en los municipios castellanos de la Baja Edad Media. Aspectos organizativos», op. cit. p. 44. 
el que vivían, condicionado a su vez por las prácticas políticas que cada lugar engendraba. En este sentido, se sabe que la práctica de conceder señoríos a particulares no limitaba la autonomía de los concejos sino que reforzaba el poder de sus elites. Entendemos que de forma conexa también se reforzaban políticamente los pecheros enriquecidos de lo que antiguamente había sido una porción de la Tierra de alguna villa, ya que tenían como recurso de cambio, y para negociar con un particular, años de tradición y participación en la gestión de estos términos.

En este contexto, es lógico sostener que la autoridad para dirimir cualquier tipo de subversión del orden establecido, no fuera producto de la clásica imposición vertical de la voluntad de los sectores hegemónicos de esta sociedad sobre los grupos de los no privilegiados.

Las bases sobre las que se habían estructurado, y funcionaban, las sociedades en la zona de los grandes concejos castellanos son precisamente las que sostuvieron la emergencia de los pecheros enriquecidos, especialmente los de la Tierra, como agentes políticos autónomos, aunque su participación no estuviera necesariamente reconocida en espacios políticos formales. 